\title{
Using DIR- Floor time based program to promote attachment behaviors in children with Autism Spectrum Disorders
}

\author{
Alshaimaa M. Salman \\ (Mental Health department, Faculty of Education, Minia University, Egypt)
}

\begin{abstract}
This study aimed to promote secure attachment behaviors with DIR/ Floor time based program in children with Autism Spectrum Disorders (ASD). Study sample included (7) children from a kindergarten of special needs whom diagnosed as children with ASD. Study tools were Psycho- Educational Profile - Revised (PEP-R) prepared by Schoppler et al.,1990, Child Attachment Behaviors Questionnaire (CABQ), and DIR/ Floor time based program which are both prepared for this study. The findings indicated that children with ASD (study sample) had insecure attachment behaviors (avoidant and resistant- ambivalent) and not disorganized disoriented attachment behaviors. Results showed that DIR/Floor time based program was statistically significant (at 0.05 ) to promote secure attachment behaviors and was effective to release autism in study sample from severally autistic to mildly moderately autistic.
\end{abstract}

Keywords: Attachment, Autism Spectrum Disorders (ASD), Developmental Individual Relationship (DIR), Floor time.

\section{INTRODUCTION:}

The warm, intimate, and continuous relationship between the child and his mother or caregivershould be experienced in which both can find satisfaction and enjoyment [1]. It was suggested that individuals during infancy develop Internal Working Models (IWM) of the self andothers which are determining the type of behavior that they expect from their mothers or caregivers [2]. While the ability to relate and communicate had been describedas a series of building blocks or developmental phases of interpersonal capacity [3].

IWM ofothers dictate whether one can expect assistance, includingresponsive and caring behavior, from significant others in times ofstress, whilst the IWM of the self determines how worthy one feelsin obtaining assistance [2]. Based on these assumptions, infants and adults are classified as secure or insecure with regard to attachment using standardized measures designed to activate the individual's attachment system [4].

Attachment behaviors require sensitivity and responsiveness on the part of the caregiver to contain the infant's anxieties and fears so the child can develop a stable cognitive-emotional schema of the caregiver's availability [5], reduce stress, provide comfort and protection in potentially threatening situations [6], afford emotionalaccess, respond tohis or her positive and negative states [7]. So, this relationship flows in two directions through the interactive interpersonal regulation of both of them [8].

\subsection{Attachment and autism:}

Autism was defined as a neurodevelopmental disorder with a pattern of qualitative abnormalities in three functional domains: reciprocal social interactions, communicationand restrictive interests and or repetitive behaviors [9]. Because of many of the symptoms of autism and attachment disorders are similar to each other and remain unclear in most cases, these symptoms present challenges to clinicians [10]. The fundamental ability to form attachment is essential for social relationships. Beside Attachment was defined as the evolutionary based, innate predisposition of a child to seek proximity to and contactwith a specific figure [6].So the maternal deprivation of this relationship caused stresses for a child withlifelong consequences, that the child does not grow well [11], [12], \& [13].It was notably that secure attachment supports the development of lifelong capacities for psychological stability and the capacity to form successfully intimate relationshipswith others [5], [8], [3], \& [14]. While insecure attachment may affect individual emotion-regulation and health [6]. Secure attachment in children has been associated with positive emotional and social development in nonclinical [15] \& [16] and clinical populations [17], [18], \& [19].

When the ability to seek or maintaincommunication is absent or impaired in the relationship, urgentsupport is needed [3]. By the definition of autism as a disorder of integration among various distinct brain functions [20], Believing in the strategy of "heighten the effect to strengthen connectivity" is more effective with children with autism [21]. 
IWM and attachment are expected to remain stable, but they are active constructs that may be restructured at any given time in response to stressful life experiences depending on the caregivingenvironment [22]. If the relationship substantially changes the child perception of the caregiving environment, this mayresult changes to the child IWM and possibly attachment style [23], [24], \& [25]. This may clarify the possibility of changing the child "attachment style". Attachment styles of children with autism may be influenced more by their biologically based communicative and relational constraints than by environmental factors, and that parents may be unable to prevail over these constitutional limitations [19]. On the other hand, Positive changes in social engagement and language can be made if the parents change the way they interact with their children, that in turn increasing reciprocity. In addition, Attuned relationships in infancy change brain structure in ways that later impact social and emotional development [20].

\subsection{DIR/Floor time:}

This study examined relational behaviors in children with ASD and their caregivers.It is a study of attachment - based intervention. Developmental, Individual, and Relationships based intervention (DIR) is one of positive interventions for childhood disorders. It is a functional developmental approach helps to recognize many intervention components into a comprehensive program [21]. It identifies how the child integrates all his separate abilities to relate to the social and cognitive world in a purposeful and emotionally meaningful manner [26].

DIR approach has three main components. D, Developmental; It aims to integrating the most cognitive and affective processes from six functional developmental capacities. I, It investigating individual differences in motor, auditory, visual- spatial, and other sensory processing capacities to express how the child plans, organizes and reacts responses [26]. Finally, R, means relationships that are part of child - caregiver and family interaction patterns and which provide ongoing nurturing support [21]. As a technique of DIR; Floor time is the playing component of a comprehensive program for children with ASD, The playground is a highly motivating place for most children [21], but for a child with challenges in communicating and sensory and motor abilities, it can be a stressful and difficult time [27].

1.3. DIR/ Floor time and relationships based behaviors:

DIR/ Floor time approach includes Regulation of emotional responses through sensory profile, relationships, and spontaneous communication between the child and their caregivers[28]. Floor time provides a way of making a stage set for real- life interactive relationships [26]. These relationships are tailored to the child's individual differences that move up the developmental ladder, mastering each and every functional emotional developmental capacity that the child is capable of[29].

A developmental stage can be fully mastered with a broad range of emotional themes that characterize each stage and if the child is using all his processing capacities. Children with ASD can have a deficit to reach to a stage, or can have constrictions or partial mastering of each or some stages; like emotional themes. They can often do only 5 or 6 circles while children should be able to open and close at least 50 circles at a stage [26]. The degree to which the child can get in the first four levels determines how a child develops symbols and not just scripted language.

\section{RESEARCH AIMS}

In this study, it was suggested that attachment behaviors could be exist in children with ASD, but it may be different from the other children. Stresses, the environment, caregivers, or even biological characters may influence the child "attachment style". Despite the research literatures has been differentiated about the secure or insecure attachment style in children with ASD, There are a possibility in changing the attachment style in children with ASD, But with the suitable intervention that based on relationships such as DIR/ Floor time.

So, this study aims to investigate (a) the attachment behaviors of each child of study sample before and after applying the DIR - Floor time program, (b) prepare DIR / floor time based program for study sample in a purpose of promote secure attachment style. Finally, (c) examine whether the DIR / floor time based program release autism in children of study sample.

\section{MATERIALS AND METHOD}

\subsection{Participants and Procedure}

Procedures started in September 2012 in the beginning of school academic year (2012- 2013). Study sample included two groups, First included (11) children between ages 2-11 years for testing questionnaire psychometric properties. Second, Clinical study sample included (7) preschool children whom attached to the kindergarten of special needs school, between ages 3-8 years old. They are spend a year at least in this kindergarten, with an educational program, including speech therapy. Diagnosis was determined by PEP- R, prepared by Schopler et al.,1990[30]. Afterwards children were observed for investigating attachment behaviors 
and determine child attachment style by Child Attachment Behavior Questionnaire (CABQ), which was prepared for this study. DIR- Floor time based program was prepared to promote children attachment behaviors. Each of PEP- R and Child Attachment Behavior Questionnaires (CABQ) were observed before and also directly after finishing DIR - Floor time based program.

1.5. Study tools

1.5.1. Psycho- educational Profile - Revised (PEP- R), prepared by Schopler et al., 1990

The PEP- $\mathrm{R}$ was developed to assess children with disorders such as Autism Spectrum Disorders (ASD). It provides developmental age from 6 months to 7 years throw the following areas: imitation (16 items), perception (13 item), fine motor (16 item), gross motor (18 items), eye hand coordination (15 items), cognitive performance (26 items), and cognitive verbal (27 items). Developmental scale is divided into three levels of scoring; passing, emerging and failing. A standardized developmental age score (IR) can be yield by the sum of all individual item- passing scores[30].

The PEP- $\mathrm{R}$ also includes a Behavioral Scale which covers four areas: a) relating and affect (12 items), b) play and interest in materials ( 8 items), c) sensory responses (12 items), and d) language (11 items)[30]. The third part of PEP-R is used to assess the severity of autism among the participants. Children with scores of 30.5 -37 are rated as mildly moderately autistic, and 37.5- 60 as severely autistic[30].

Coefficient of Alpha Cronbach for the whole scale was excellent $(\alpha=0.93)$, suggesting that the PEP- R in population with dual disability has high internal consistency. The domain total correlation ranged from 0.75 to 0.90 , suggesting that all domains of PEP- $\mathrm{R}$ significantly contributed to the total developmental age and developmental score of PEP- R (Table 1)[31].

Table (1): Internal consistency and domain - total correlation of PEP-R

\begin{tabular}{l|l|l}
\hline \hline PEP- R domain & Internal consistency & Domain- total correlation \\
\hline \hline Imitation & 0.91 & 0.85 \\
\hline Perception & 0.93 & 0.75 \\
\hline Fine motor & 0.91 & 0.85 \\
\hline Gross motor & 0.92 & 0.78 \\
\hline Eye hand coordination & 0.92 & 0.84 \\
\hline Cognitive performance & 0.91 & 0.90 \\
\hline Developmental score & 0.93 & 0.75 \\
\hline \hline
\end{tabular}

\subsubsection{Child Attachment Behaviors Questionnaire (CABQ)}

Child Attachment Behaviors Questionnaire (CABQ) was utilized for this study by the researcher to determine changes in child attachment behaviors over time in relational situations, define the child attachment style, and attachment difficulties that it is a time by attending the attachment style subscale of the highest degree. The questionnaire was developed based on a comprehensive review of autism, child attachment literature, and behavior observations in children with ASD. In addition; the questionnaire was developed carefully to be suitable for the study sample otherwise some common questionnaires for measuring child attachment like; Dimensions of Temperament Revised (DTR), Randolph Attachment Disorder Questionnaire (RADQ), Child Attachment Questionnaire (CAQ), and Kinship Center Attachment Questionnaire (KCAQ). DTR is based on changes in mood to recognize specific attachment in children with ASD while RADQ was prepared for investigating just insecure disorganized- disoriented attachment style [32]. Only three situations of attachment evaluation in CAQ, so, it is good for infants between 12-18 months to investigate the attachment style. CAQ is not enough to recognize and define changes in attachment behaviors for a child with ASD, but using KCAQ makes some confusion about the attachment behavior and some behaviors that consider symptoms or diagnosis signs of autism (as it was referred in DSM- 5 [9]). For children with ASD, the traditional child attachment instruments may lead to invalid inferences because they assume child attachment style is present and so seek only to describe it. It is good to define behaviors that indicate child attachment apart of behaviors that indicate autism to lead to valid measures for attachment in children with ASD.

\subsubsection{Attachment behavior definition:}

There are some reasons for preparing a new questionnaire for the clinical sample "children with ASD". It was observed that the child with ASD has a specific way of attachment and not all the literatures about the attachment in children with ASD confirmed that this specific child may have a deficit of attachment or attachment disorders. It can be possible for him/ her to have his/ her own style of attachment. In the present study, Attachment is a multi direction relational behavior between the child and a specific figure (a new 
caregiver) that helps him to develop his perception about communication, stressful situations, and / or social interactions.

The present study defines the different attachment styles as follow; Secure attachment style, It is some attachment behaviors that help the child to develop a positive working model of himself and others, to have an expectation that assistance would be available in times of need and that the child is worthy of such assistance. While Insecure attachment style is some attachment behaviors which divided into three styles; the first is Resistant-ambivalent attachment style, In which the child develops a negative working model of himself and others, to have an expectation that assistance would be inconsistent in times of need and that the child is not worthy of such assistance. The second is Avoidant attachment style; in which the child develops a negative working model of others, and to have an expectation that assistance would not be received when required, Because of the development of feelings of unworthiness regarding others affection whilst also becoming suspicious of any affection he may receive. Finally, the third type of insecure attachment is disorganized which was suggested by Main and Solomon, 1986; Insecure disorganized attachment style: In which the child displays disorganized, disoriented, and confused behaviors during reunions [19].

Due to the previous definitions, the questionnaire in its first step consists of five subscales; specific behaviors of autism, secure attachment style, insecure avoidant attachment style, insecure resistant- ambivalent attachment style and disorganized- disoriented attachment style. Each subscale consists of (10 items). With the present study definition of Attachment behavior, the items contributed on three dimensions about child behavior in social interactions with caregiver; support communication with environment, and stressful situation. The questionnaire is filled in a week of observation in the kindergarten.

\subsubsection{Psychometric properties of CABQ:}

The questionnaire in its first step was revised by three reviewers; before testing its psychometric properties, for a sample of (11) children with ASD. Using correlations between the item degree and total item degree of the subscale, Data in the next table clarifies results of testing questionnaire validity.

Table (2): Results of testing questionnaire validity $(\mathrm{n}=11)$

\begin{tabular}{l|l|l|l|l|l}
\hline \hline Items & Ss. 1 & Ss. 2 & Ss. 3 & Ss. 4 & Ss. 5 \\
\hline \hline It. 1 & -0.319 & $0.907(* *)$ & 0.224 & $0.790(* *)$ & $0.804(* *)$ \\
\hline It. 2 & 0.393 & $0.880(* *)$ & $0.653(*)$ & $0.793(* *)$ & $0.663(*)$ \\
\hline It. 3 & -0.342 & $0.849(* *)$ & $0.820(* *)$ & $0.648(*)$ & $0.804(* *)$ \\
\hline It. 4 & 0.344 & $0.768(* *)$ & 0.583 & $0.759(* *)$ & $0.652(*)$ \\
\hline It. 5 & 0.516 & 0.356 & $0.931(* *)$ & 0.275 & 0.014 \\
\hline It. 6 & -0.099 & $0.751\left(^{* *}\right)$ & $0.940(* *)$ & $0.897(* *)$ & 0.547 \\
\hline It. 7 & 0.383 & $0.763(* *)$ & $0.723(*)$ & $0.761(* *)$ & 0.494 \\
\hline It. 8 & 0.543 & $0.960(* *)$ & $0.821(* *)$ & $0.880(* *)$ & $0.842(* *)$ \\
\hline It. 9 & 0.500 & $0.853(* *)$ & $0.939(* *)$ & $0.908(* *)$ & $0.804(* *)$ \\
\hline It. 10 & 0.563 & $0.699(*)$ & $0.966(* *)$ & 0.114 & $0.658(*)$ \\
\hline \hline
\end{tabular}

$(* *)$ : significant at 0.01 level

(*):significant at 0.05 level

As it was showed in table (2) the first subscale of specific behaviors of autism (Ss1) was omitted because of not statistically significantly results. The other four subscales, with their items and item total correlations were all statistically significant at the 0.01 level with the exception of items 10 in the second subscale of secure attachment style (Ss2), 2 and 7 of the third subscale of insecure avoidant (Ss3), 3 of the forth subscale of insecure resistant - ambivalent (Ss4), and items 2,4 and 10 of the fifth subscale of insecure disorganized - disoriented attachment style (Ss5), which correlated statistically significantly at the 0.05 level. Item 5 of Ss2, Items 1 and 4 of Ss3, Items 5 and 10 of Ss4, items 5,6, and 7 of Ss5, which did not correlate statistically significantly with the total score, were deleted. CABQ after deleted items, has four subscales; secure attachment style ( 9 items), Insecure avoidant attachment style ( 8 items), Insecure resistant - ambivalent attachment style (8 items), And insecure disorganized - disoriented attachment style (7 items).

Questionnaire reliability was investigated for the non clinical sample $(n=11)$ children. The deletion of any one item from the scale did not resulted in a notable improvement in alpha. With split half results, Questionnaire reliability was statistically significant for each subscale and item. The next table clarifies results of alpha coefficient and split half for each subscale and item. 
Table (3): Results of alpha coefficient and split half for each subscale $(n=11)$

\begin{tabular}{l|l|l}
\hline \hline CABQ subscales & $\begin{array}{l}\text { alpha } \\
\text { coefficient }\end{array}$ & $\begin{array}{l}\text { split half } \\
\text { reliability }\end{array}$ \\
\hline \hline secure attachment & .941 & .924 \\
\hline Insecure avoidant attachment & .944 & .959 \\
\hline Insecure resistant ambivalentattachment & .927 & .941 \\
\hline Insecure disorganized- disorientedattachment & .844 & .784 \\
\hline \hline
\end{tabular}

With these findings, The CABQ has statistically significant psychometric properties (validity and reliability). Thus, It is valid to investigate child attachment behaviors and discriminate between Attachment styles for clinical sample (children with ASD.

1.5.3. DIR/ Floor time based program:

In the present study DIR/ Floor time based program is defined as: "a comprehensive intervention of developing basic personal habits and improving visual and auditory skills throw fully interactive floor time games with caregiver which dictate secure attachment behaviors and implement relationships with others in a purpose of releasing autism". DIR based program has three basic kinds of aims; developmental aims, individual aims, and relationship aims.

Table (4): DIR based program aims

\begin{tabular}{|c|c|c|c|}
\hline Main objectives & \multicolumn{2}{|c|}{ Specific objectives } & $\begin{array}{l}\text { Therapeutic } \\
\text { Types }\end{array}$ \\
\hline $\begin{array}{l}\text { - Improve system sensitivity. } \\
\text {-Share attention with } \\
\text { activities. }\end{array}$ & \multicolumn{2}{|c|}{$\begin{array}{l}\text { - Raise awareness of the changes in } \\
\text { rhythmic. } \\
\text { - Utilize effectively the basic tools and } \\
\text { techniques of plastic. }\end{array}$} & $\begin{array}{l}\text { Music therapy } \\
\text { Art therapy }\end{array}$ \\
\hline \multicolumn{4}{|l|}{ 2- Individual differences } \\
\hline Main objectives & \multicolumn{2}{|c|}{ Specific objectives } & $\begin{array}{l}\text { Therapeutic } \\
\text { Types }\end{array}$ \\
\hline $\begin{array}{l}\text { - Improve speech organs. } \\
\text {-Improve visual and } \\
\text { auditory capacities. } \\
\text { - Improve the overall } \\
\text { efficiency of the body. } \\
\text {-Reduce / increase } \\
\text { hypersensitivity or arousal. }\end{array}$ & \multicolumn{2}{|c|}{$\begin{array}{l}\text {-Expand vocabulary. } \\
\text { - Develop the habit of good posture. } \\
\text { - Improve hand-eye coordination. } \\
\text { - Improve gross motor skills. } \\
\text { - Increase lung capacitive life through } \\
\text { breathing exercises. }\end{array}$} & $\begin{array}{l}\text { Physiotherapy } \\
\text { Rehabilitation } \\
\text { Speech therapy } \\
\text { Sensory } \\
\text { integration }\end{array}$ \\
\hline \multicolumn{4}{|l|}{ 3- Relationships Aims } \\
\hline \multicolumn{2}{|l|}{ Main objectives } & Specific objectives & $\begin{array}{l}\text { Therapeutic } \\
\text { Types }\end{array}$ \\
\hline \multicolumn{2}{|l|}{$\begin{array}{l}\text {-Develop forms of contact with } \\
\text { other people. } \\
\text { - Develop communication skills } \\
\text { based on closeness and touch. } \\
\text {-Improving social skills. }\end{array}$} & $\begin{array}{l}\text {-Exercise imitation skills. } \\
\text {-create a network of subject, } \\
\text { word, image, and symbol. } \\
\text {-interacting with peers. }\end{array}$ & $\begin{array}{l}\text { Alternative } \\
\text { communication } \\
\text { Pet therapy }\end{array}$ \\
\hline
\end{tabular}

Each type of therapeutic has some procedures and circles the child has to end. The ending point of each circle is an obvious behavior that clarifies that the child makes a progress to success in a developmental phase. Floor time conceders the main technique of the DIR based program. To prepare the floor time games, it was first applying a child case study to investigate the child preferable animals and places. According to case study, the farm game considered the main procedure of floor time. It was a story game prepared like the daily main activities of the child that offered amusement activity and problem solving.

Following the child lead was the second step for preparing the floor time based game. Then join the child's world with the appropriate role in a story game to help the child develop each of his functional emotional capacities. Dresses of the farm animals with feathers and hairs served as tools of sensory integration that develop the child awareness to relate and communicate. 


\section{RESULTS:}

As it was the first aim of this study to investigate attachment behaviors in study sample (children with ASD) pre and after applying DIR - Floor time based program, it was found that the children have insecure attachment behaviors that contributed into two children with insecure avoidant attachment behavior and five children with insecure resistant - ambivalent attachment behaviors. Children neither have secure attachment behaviors nor insecure disorganized- disoriented attachment behaviors. After applying the DIR / Floor time based program, It was found that each of the children has secure attachment behaviors. The next table clarifies $\mathrm{Z}$ value and significances with wilcoxon nonparametric test of each attachment behaviors styles.

Table (5): Wilcoxon nonparametric test of each attachment behaviors styles

\begin{tabular}{|c|c|c|c|c|c|}
\hline \multirow[t]{2}{*}{ Variables } & \multicolumn{2}{|c|}{ means } & \multicolumn{2}{|c|}{ sum } & \multirow{2}{*}{$\begin{array}{c}\mathrm{Z} \\
\text { value }\end{array}$} \\
\hline & $\begin{array}{c}\text { Nega } \\
\text { t. }\end{array}$ & Posit. & $\begin{array}{c}\text { Nega } \\
\text { t. }\end{array}$ & Posit. & \\
\hline Secure attachment style & 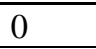 & 4 & 0 & 28 & $* 2.375$ \\
\hline Ins. Avoidant attachment style & 4 & 0 & 28 & 0 & $* 2.375$ \\
\hline $\begin{array}{l}\text { Ins. Resistant - ambivalent attachment } \\
\text { style }\end{array}$ & 4 & 0 & 28 & 0 & $* 2.371$ \\
\hline $\begin{array}{llll}\text { Ins. Disorganized } & - & \text { disoriented } \\
\text { attachment style } & & \end{array}$ & 3 & 0 & 15 & 0 & $* 2.060$ \\
\hline
\end{tabular}

(*): significant at 0.05

As it was clarified in table (4) $\mathrm{Z}$ values was statistically significant at (0.05) of each attachment behavior style. Total degree of each subscale of insecure attachment behavior was significantly less after applying DIR/ Floor time based program than before applying it. While total degree of secure attachment behavior was significantly more than before applying DIR/ Floor time based program. The next table has results of wilcoxon nonparametric test of PEP-R with IR, total behavioral scale and CARs.

Table (6): Wilcoxon nonparametric test of PEP-R

\begin{tabular}{l|l|l|l|l|l}
\hline \hline \multirow{2}{*}{ Variables } & \multicolumn{2}{c|}{ means } & \multicolumn{2}{c|}{ sum } & \multirow{2}{*}{ Z value } \\
\cline { 2 - 6 } & Negat & Posit. & Negat & Posit. & \\
& & & & & \\
\hline \hline IR & 0 & 4 & 0 & 28 & $* 2.366$ \\
\hline Behavioral subscale & 4 & 0 & 0 & 28 & $* 2.375$ \\
\hline CARs & 4 & 0 & 28 & 0 & $* 2.366$ \\
\hline \hline
\end{tabular}

(*): significant at 0.05

a. These findings indicated that with four months / five days a week of applying DIR Floor time based program for the children with ASD, the children developmental age was significantly developed with (0.05). The developmental, behavioral and CARs subscale of PEP-R was significantly with (0.05) developed after applying the DIR/ Floor time based program.

\section{DISCUSSION:}

Results of the first aim of this study indicated that children with ASD (clinical sample), have insecure attachment behavior. As a recommendation of a correlation study that it would be most helpful in clarifying the compatibility of autism and attachment theory by identifying the existence of attachment transmission in cases of children with ASD[33].These results agree with findings of Maunder \& Hunter, 2001 and Buchheim, et al., 2009 that insecure attachment contributes to a wide spectrum of mental disorders[34], and [35], And in children with autism toward their mothers[36], [37], [38], [39], [40], [41], [42], [43], [44], \&[45]. Results of these studies place great demands of their parents in cultivating secure attachments and fostering their development[33], and [19].Despite the bleak implications of theoretical models assuming that number of securely-classified children with autism was lower than that of children without autism [33], children with autism and associated disorders are unable to form secure attachment relationships [47], \& [48]. Results of the present study after applying DIR/ Floor time program indicated that children with autism of clinical study have secure attachment behaviors in agreement with number of previous studies which had reported secure attachment behaviors in children with 
autism toward their mothers [19].

The present study suggested that there is no evidence that children with autism don't experience secure attachment behavior. In addition They displayed secure attachment behaviors toward their mothers when distressed[39], \&[40], discriminated between their mothers and strangers, and tended to increase their proximity-seeking behaviors when reunited with their mothers after separation, similar to children in control groups (e.g.,[36], [43], [44], \& [45]. It was further noted that children with autism whom was demonstrating secure attachment patterns responded more frequently to bids for joint attention [38], made more frequent requests [37]; and displayed greater ability in their receptive language than did children whom was demonstrating insecure attachment patterns[37], [41], [42], \& [19].

Children with autism can have their own style of attachment behavior. Autistic and typical children's manifested attachment behavior without significantly differences with normal children at a younger age. While quality of attachment didn't correlate with diagnosis, developmental quotients, mood change, or behavior change on separation in the developmentally disordered group [49]. Secure attachment behavior in early relationships through building the bonds of love is essential to make a good start in life [50]. Healthy relationships support the adaptation of the infants towards the internal regulation functions [8].

Because of the necessity of secure relationships, this study aimed to prepare a new questionnaire for attachment behaviors and styles for children with autism. They may have a special behavior for attachment. Attachment formation may involve different processes in autistic children than that in non autistic children of equivalent intellectual level[42]. Thus, a questionnaire for attachment must differentiate between behaviors that conceder signs of attachment and the others of autism. Attachment is the first phase of relationships that encourage communication and social interaction with the environment. So, Studying attachment behaviors for the suitable relationships - based intervention, is a good start to release autism. But healthy communication and social interaction start from when the child develops secure attachment behaviors. Secure attachment helps the child to develop his perception about his environment. The child starts to pay attention to his environment then feel save in it with support of his caregiver who helps the child to explore his environment.

To release autism, it must be considered that compared to typically developing children, children with autism may require stronger and more explicit sensory stimulation from their parents. Attachment security may look different in children with autism compared with their typically developing peers; that attachment behaviors, such as seeking contact with and proximity to caregivers, may serve different functions for this population [33]. The integrated intervention looks to the hall child not just symptoms, signs, behaviors, or cognitive. Integrated comprehensive interventions like DIR look to the child developmental capacities, and strengthen them to help the child to build his perception about his auditory and visual abilities through healthy relationships; full with intimate, warm, and confidence. Such intervention can change and increase the connectivity between different areas of the brain for children with autism [21]. DIR seems to be the most appropriate intervention to promote attachment in this study for children with autism. It is becoming one of the most common forms and a viable option of intervention for children and adolescents with developmental delays especially Autism spectrum disorders (ASD) and their families [20] \& [29]. For this intervention, it requires a comprehensive program that is designed according to six developmental levels of; a) sharing attention and regulation, b) engagement with warmth, trust and intimacy, c) affective reciprocity and gestural communication, d) shared social communication and problem solving, e) functional use of ideas, and f) logical and abstract use of ideas and thinking.

Playfully obstructive strategies such as floor time, help in procedures of such comprehensive program. The child, who experiences difficulties in using social pragmatic language like ASD, starts with one to one intervention because that would be effective, necessary and facilitating. The child has to get involved with someone who is very animated to give an exaggerated emotional response which is often gestural at first and not verbal [51]. With individual intervention at the beginning, the caregiver wooed the child into relating using a lot of sensory and motor activities [51]. The new caregiver (the researcher) had prepared a case study for a child and changes in attachment behavior through the daily activity. Activity such floor time playfully games, was designed to help the child regulate and soothe by dealing with repetitive and perseveration behaviors [21]. From this step, when the child is developmentally ready for peer interventions, then it can be starting with a small group. Peers can have the opportunities to begin to interpret meanings of gestures, facial expressions and affect cues in playing games without the use of verbal language. Within the small group, activities that work to build mutual relationships between peers while supporting social pragmatic language goals are essential [27].

When group intervention based program get started, the caregiver helps the child to close a circle. Procedures of such intervention were carried side by side with the kindergarten educational program. DIR program included home works that the parents did with their children at home. They adapted their interactions and responsiveness with their child, in order to be successful with the intervention as it was recommended by 
Olsen,[28].Diagnosis of autism, applying program and evaluating were done by the same team. DIR/ Floor time based program with relationships based aims develop the child ability to relate and communicate, and improve the efficiency of his body by learning basic habits for personal health and self service with not neglecting that the child with autism has a deficit in speech so the program provide (to enhance) the child visual and auditory abilities and expand his vocabulary. Floor time based games following the child's lead of his natural interests and desires then use that into a validating emotional experience. Joining the child's world with the right kind of support is useful to help him master each of his functional emotional developmental capacities [51]. This encourages both self awareness and improved techniques as one enters a child world and tailors interactions to the child's specific nervous system [20].

The child's lead is hard to be followed if the child doesn't have one but by searching about interests and desires in the child case study it can be found. In the present program one of the children had a prefer of studying (writing letters, matching, and coloring pictures) and a prefer of repeating some words of the advertisements, he was laughing just at the mouse pictures. His role in the story game was to act as a mouse jumping, writing, collecting pictures and put them in the appropriate place in the shapes. Problem solving was included in game activity to help the child to strengthen his developmental capacities such as "The dog likes to buy a shoe, but how to wear it by his own". Circles of this developmental level are how to wear a shoe by his own, then putting the string in the appropriate hole, and tie them. But there are sublevels developmental capacities in which child with autism differ from the other children. Children with ASD tend to have a harder time integrating these different capacities meaningfully [21]. The child may take more time or doesn't can end the circle in the time that the other ASD children can end two or three circles. So this child was replaced the shoe with a string with a shoe with a scotch.

DIR/ Floor time based program was effective to promote attachment behaviors in clinical sample and also to release autism in clinical sample (Children with ASD). Children with ASD (clinical sample) were severally autistic except one child was moderately autistic as they were diagnosed by the CARs subscale of PEP-R. After applying the DIR/Floor time based program it was found all of the children were diagnosed as moderately autistic. Result indicated that the DIR/Floor time based program was effective to release autism in study sample. Although each of the children has a different time to end a circle. They were all successful to end the program together as it was planned. This is because of the diversity of activities that prepared to the child lead to facilitate the child enjoyment with the activity. In addition, the farm game had some animals which chosen according to the child preferable.

The child lead to a specific animal encourages the basic core of relationships and / or attachment. The chosen animal by the child may be considered as an intellectual function that based on comparing and choosing which is considered as a problem solving and making decision. While engaging in an activity game the child liked to imitating some moves and interacting because he chose to play the role of a specific animal. Imitation of the animal sounds toke steps. The first step was to listen to the animal sounds then recognize it between some sounds and pictures. Finally the child played a role of the animal in an activity story game.

\section{CONCLUSION}

The study assumed in its first step that according to the review of autism, a) the children with Autism Spectrum Disorders (ASD) can have their own attachment, b) they can have secure attachment style, and c) based on the review article of intervention, such interventions of promoting the basic core of relationships could be found. So, the study aimed to promote secure attachment behaviors with DIR/ Floor time based program in children with (ASD), as a proposal step to release autism. Study limitations was (7) children from a kindergarten of special needs in Poland whom diagnosed with Psycho- Educational Profile - Revised (PEP-R) prepared by Schoppler et al.,1990, as children with ASD. Preparing a questionnaire for defining attachment like Child Attachment Behaviors Questionnaire (CABQ), and promoting attachment like DIR/ Floor time based program, was an important aim for this study. The findings indicated that children with ASD (study sample) had insecure attachment behaviors (avoidant and resistant- ambivalent) and not disorganized - disoriented attachment behaviors. Results showed that DIR/Floor time based program was statistically significant (at 0.05 ) to promote secure attachment behaviors and was effective to release autism in study sample from severally autistic to mildly moderately autistic. The research procedures had been carried out daily at the time of playing. The farm game was the main core of the floor time program. It could be recommended that the farm game procedures could include a compatible program for the child with ASD concerning his compatible development instead of using separating programs for deferent aims.

\section{ACKNOWLEDGMENTS}


The author did not receive any financial support for the research, authorship, and/ or publication of this article. She worked as a volunteer in the school which the author applied the research in it. The author would like to be thankful for Warsaw University for Life Sciences, especially Dr. Krystena Najder, Dr. Ewona Stefaniak, and Skierniwieca school for special needs especially for the psychological department for their help and facilitating the research procedures.

\section{REFERENCES:}

[1] J. Bowlby, Maternal care and mental health. Bulletin of the World Health Organization , 3, 1951, 353534.

[2] J. Bowlby, Attachment and loss: Vol. 2. Separation anxiety and anger. (New York: Basic Books, 1973).

[3] D. Stern, The interpersonal world of the infant: A view from psychoanalysis and developmental psychology (second edition ed.) (New York: Karnac Books, 2000).

[4] D. Westen, O. Nakash, C. Thomas, R. Bradley, Clinical assessment of attachment patterns and personality disorder in adolescents and adults, Journalof Consultant Clinical Psychology, 74, 2006, 1065- 1085

[5] W. Winnicott, The maturational processes and the facilitating environment (London: Hogarth Press, 1965).

[6] J. Bowlby, Attachment and loss, vol. 1: Attachment. (New York: Basic Books, 1969).

[7] A. Schore, The effects of early relational trauma on right brain development, affect attunement, and infant mental health, Infant Mental Health Journal , 22, 2001, 201-269.

[8] B. Beebe, and F. Lachmann, Co-constructing inner and relational processes: Self and mutual regulation in infant research and adult treatment, Psychoanalytic, 1998.

[9] M. Kring, L. Johnson, C. Davison, and M. Neale, Abnormal psychology, Diagnostic and statistical manual of mental disorders DSM- 5, (4th. ed.), (Washington, DC: American Psychiatric Association, 2014)

[10] B. Dogangum, A glance in to the relationship between autism and reactive attachment disorder, Neuropsychiatrie de l'enfance et de l'adolescence, 60, 2012, 64-126.

[11] J. Bowlby, and J. Robertson, A two-year-old goes to hospital,Proceedings of the Royal Society for Medicine , 46, 1952, 425-427.

[12] J. Robertson, A child goes to hospital Film ( London: Tavistock Child Development Research Centre, 1953)

[13] M. Ainsworth, M. Blehar, E. Waters and S. Wall, Patterns of attachment: A psychological study of the strange situation, Hillsdale, NJ: Erlbaum,Psychology, 15, 1978, 480-516.

[14] C. Trevarthen, Intrinsic motivations for companionship in understanding: Their origins, development, and significance for infant mental health, Infant Mental Health Journal , 22, 2001, 95-131.

[15] F. Becker-Stoll, , A. Delius, and S. Scheitenberger, Adolescents' nonverbal emotional expressions during negotiation of a disagreement with their mothers: An attachment approach. International Journal of Behavioral Development, 25, 2001, 344-353.

[16] M. Steele, H. Steele, M. Johansson, Maternal predictors of children's social cognition: An attachment perspective, Journal of Child Psychology and Psychiatry , 43, 2002, 861-872.

[17] A. Oyen, S. Landy, C. Hillburn-Cobb, Maternal attachment and sensitivity in an at-risk sample, Attachment \& Human Development, 2, 2000, 203-217.

[18] M. Main, E. Hesse, Parents' unresolved experiences are related to infant disorganized attachment status: Is frightened and/or frightening parental behavior the linking mechanism, 1991.

[19] L. Seskin, E. feliciano, G. Tippy, R. yedloutschnig, M. Sossin, A. Yasi, Attachment and Autism: parental attachment representations relational behaviors in the parent - child dyad, Journal Abnormal Child Psychology, 38, 2010, 949-960.

[20] D. Siegel, Toward an interpersonal neurobiology of the developing mind: Attachment relationships "mindsight", and neural integration, Infant Mental Health Journal , 2001, 67-94.

[21] S. Greenspan, DIR/ Floortime, vally CoPA (Community of Practice in Atism), 2008. Retrieved from http://www.icdl.com/dirfloortime/.

[22] R. Kissgen, M. Krischer, V. Kummetat, R. Speiss, R. Schleiffer, and K. Sevecke, Attachment representation in mothers of children with ADHD, Psychopathology, 42, 2009, 201-208.

[23] S. Weinfield, L. Whaley, and B. Egeland, Continuity, discontinuity, and coherence in attachment from infancy to late adolescence: sequelae of organization and disorganization, Attachment \& Human Development, 6 (1), 2004, 73-97. 
[24] L. Davis, and S. Jowett, Investigating the interpersonal dynamics between coaches and athletes based on fundamental principles of attachment, Journal of Clinical Sport Psychology, 4, 2010, 112-132.

[25] L. Felton, S. Jowett, Attachment and well-being: The mediating effects of psychological needs satifaction within the coacheathlete and parenteathlete relational contexts, Psychology of Sport and Exercise , 14, 2013, 57-65.

[26] S. Greenspan, DIR/ Floortime, vally CoPA (Community of Practice in Atism), 2008. Retrieved from http://www.icdl.com/dirfloortime/.

[27] S. Greenspan, and S. Wieder, Developmental patterns and outcomes in infants and children with disorders in relating and communicating: A chart review of 200 cases of children with autistic spectrum diagnoses, Journal of Developmental and Learning Disorders , 1, 1997, 87-141.

[28] S. Olsen, (2012), What is the effectiveness of the DIR/ Floortime model on regulatingg emotions in autism spectrum disorders, (CAT, Critically Appraised Topic Worksheet,AOTA)

[29] S. Greenspan, Floortime: What is really is and what it isnot, Interdisciplinary Council on Developmental and Learning Disorders (ICDL), 2012, Retrived from http://www.icdl.com/elirfloortime/newsletter/floortimewhatitreallyisandisnt.shtml.

[30] E. Schopler, R. Reichler, R. Devellis, and K. Daly, Towards objective classification of childhood autism: childhood autism rating scale (CARS), (1), 1990, 91-103.

[31] A. Merlin, J. Rachel, D. Anna, A. Julie, S. Satya, M. Priya, Psychometrics and utility of PsychoEducational Profile - Revised as a developmental quotient measure among children with the dual disability and autism, Journal of Intellectual Disabilities , 3, 2012, 193 - 203.

[32] M. Randolph, Manual for the Randolph Attachment Disorder Questionnaire (RADQ) (Evergreen: Attachment center press, 1997).

[33] Kappenberg, E. S., \& Halpern, D. F. (2006). Kinship Center Attachment Questionnaire: Development of a caregiver - completed attachment measure for children younger than 6 years. Educational and Psychology Measurment, 66 (5), 852-873.

[34] A. Rutgers, H. Van IJzendoorn, J. Bakermans-Kranenburg, H. Swinkels, E. Van Daalen, and E. Dietz, Autism, attachment and parenting: A comparison of children with autism spectrum disorder, mental retardation, language disorder, and non-clinical children, Journal of Abnormal Child Psychology , 37, 2007, 958-870.

[35] R. Maunder, and J. Hunter, Attachment and psychosomatic medicine: developmental contributions to stress and disease, Psychosomatic Medical , 63, 2001, 556-567.

[36] A. Buchheim, M. Heinrichs, C. George, D. Pokorny, E. Koops, P. Henningsen, Oxytocin enhances the experience of attachment security, Psychoneuroendocrinology, 34, 2009, 1417-1422.

[37] P. Bernabei, L. Camaioni, and G. Levi, An evaluation of early development in children with autism and pervasive developmental disorders from home movies: Preliminary findings. Autism , 2, 1998, 243- 258.

[38] L. Capps, M. Sigman, and P. Mundy, Attachment security in children with autism. Development and Psychopathology, 6, 1994, 249-261.

[39] T. Charman, Why is joint attention a pivotal skill in autism? Philosophical Transactions of the Royal Society of London, Series B, Biological Sciences, 358, 2003, 315-324.

[40] C. Dissanayake, S. Crossley, Proximity and sociable behaviours in autism: Evidence for attachment, Journal of Child Psychology and Psychiatry, 37, 1996, 149-156.

[41] C. Dissanayake, S. Crossley, Autistic children's responses to separation and reunion with their mothers, Journal of Autism and Developmental Disorders , 27, 1997, 295-312.

[42] J. Rogers, S. Ozonoff, C. Maslin-Cole, Developmental aspects of attachment behavior in young children with pervasive developmental disorders, Journal of the American Academy of Child and Adolescent Psychiatry, 32, 1993, 1274-1282.

[43] J. Rogers, S. Ozonoff, and C. Maslin-Cole, A comparative study of attachment behavior in young children with autism or other psychiatric disorders, Journal of the American Academy of Child and Adolescent Psychiatry, 30, 1991, 483-488.

[44] M. Sigman, P. Mundy, Social attachments in autistic children, Journal of the American Academy of Child and Adolescent Psychiatry, 28, 1989, 74-81.

[45] M. Sigman, J. Ungerer, Attachment behaviors in autistic children, Journal of Autism and Developmental Disorders , 14, 1984, 231-243.

[46] E. Stahlecker, and C. Cohen, Application of the Strange Situation attachment paradigm to a neurologically impaired population, Journal of Child Development , 56, 1985, 502-507.

[47] S. Baron-Cohen, Are autistic children "Behaviorists"? An examination of their mental-physical and appearance-reality distinctions, Journalof Autism and Developmental Disorders , 19, 1989, 579-600. 
[48] S. Baron-Cohen, Do people with autism understand what causes emotion?, journal of Child Development, 62, 1991, 385-395.

[49] T. Shapiro, M. Sherman, G. Calamari, and D. Koch, Attachment in autism and other developmental disorders, Journal of the American Academy of Child and Adolescent Psychiatry, 26 (4), 1987, 480-484.

[50] S. Gerhardt, Why love matters: How affection shapes a baby's brain, (London: Routledge, 2004).

[51] S. Greenspan, S. Wieder, J. Raphael, and M. Witten, Thebest practices, Interdisciplinary council on developmental \& Learning Disorders, ICDL. Retrieved from http://www.icdl.com/thebestpractices/ 